\title{
Centenarians and diet: what they eat in the Western part of Sicily
}

\author{
Sonya Vasto ${ }^{1,3^{*}}$, Claudia Rizzo ${ }^{2,3}$ and Calogero Caruso ${ }^{2,3}$
}

\begin{abstract}
This paper pays attention to the modifiable lifestyle factors such as diet and nutrition that might influence life extension and successful ageing. Previous data reported that in Sicily, the biggest Mediterranean island, there are some places where there is a high frequency of male centenarians with respect to the Italian average. The present data show that in Sicani Mountain zone there are more centenarians with respect to the Italian average. In fact, in five villages of Sicani Mountains, there were 19 people with an age range of 100-107 years old from a total population of 18,328 inhabitants. So, the centenarian number was 4.32 -fold higher than the national average (10.37 vs. 2.4/10,000); the female/male ratio was 1.1:1 in the study area, while the national ratio is 4.54:1. Unequivocally, their nutritional assessment showed a high adherence to the Mediterranean nutritional profile with low glycemic index food consumed. To reach successful ageing it is advisable to follow a diet with low quantity of saturated fat and high amount of fruits and vegetables rich in phytochemicals.
\end{abstract}

Keywords: Ageing, Centenarian, Longevity, Mediterranean diet

\section{Introduction}

The Mediterranean diet has been widely recommended for a healthy lifestyle since Ancel Keys first used the term in 1975 [1]. The essential concept is that this is not a set of changes to our usual diet dictated by scientific experiments, but a set of food habits and recipes traditionally enjoyed by the ordinary people of Mediterranean countries, who have been found to have lower rates of coronary and other age-related chronic diseases, including cancer, than most developed countries $[2,3]$.

In recent years, researchers have been extremely interested in the clear advantage of the Mediterranean nutritional recommendation that exists and is used in the Mediterranean surrounding area. In fact, there is no single Mediterranean diet but several interpretations based on the Mediterranean country's political, economic and cultural tradition [4].

Since 1990, increasing evidence suggests that these diets have a beneficial influence on several diseases such as cardiovascular diseases, metabolic syndromes, hence

\footnotetext{
*Correspondence: sonya.vasto@unipa.it

${ }^{1}$ Department of Molecular and Biomolecular Sciences (STEMBIO),

University of Palermo, Via Archifari 32, 90213, Palermo, Italy

${ }^{3}$ Immunohaemathology Unit, University Hospital, University of Palermo, Via

del Vespro, 127, 90137, Palermo, Italy

Full list of author information is available at the end of the article
}

showing protective effect on health and longevity [5-7]. Mediterranean diet is characterized by a high intake of monounsaturated fat, plant proteins, whole grains (fish is not always present), moderate intake of alcohol, and low consumption of red meat, refined grains, and sweets. Further, the consumption of large amount of olive oil and olives in meals dominates all the Mediterranean cuisine [8].

Historically, the beneficial properties of virgin olive oil were attributed to the high proportion of monounsaturated fatty acids (MUFAs), namely oleic acid, rather than to the phenolic fraction. Nevertheless, several seed oils, including sunflower, soybean, and rapeseed, rich in MUFA have been demonstrated to be ineffective in beneficially altering chronic disease risk factors. Therefore, it is likely that the polyphenols in olive oil may mediate these health benefits $[8,9]$.

There are at least thirty-six structurally distinct phenolics that have been identified in virgin olive oil, but not all phenolic compounds and their concentration are present in every virgin olive oil. Such differences in the phenolic compound are dependent on several factors like the variety of the olive fruit, the region in which the olive fruit is grown, the agricultural techniques used, the maturity of the olive fruit at harvest, the extraction process and the storage method [10]. 
The Sicanian Mountains (or Sicani), bordered by Ficuzza wood in the North, Caltanissetta in the East, Salemi in the West and Agrigento to the South represent a very peculiar area where there is a high frequency of centenarians with respect to the Italian average $[11,12]$. The goal of this study was to characterize the dietary

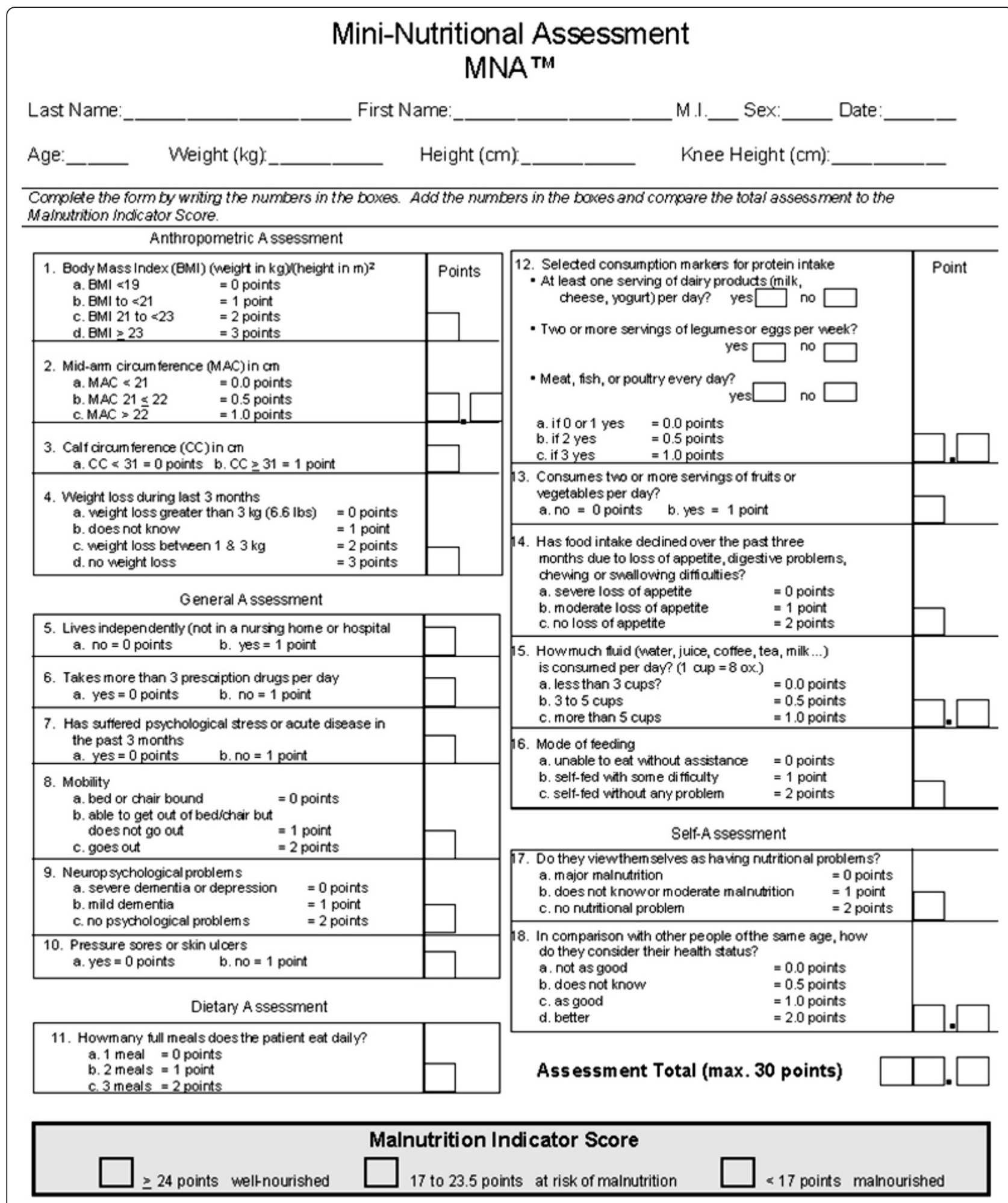

Figure 1 Example of MNA administered to healthy centenarians. 
habits of centenarians residing around the Sicani mountains, in 5 villages, namely Giuliana, Bisacquino, Castronovo, Chiusa Scalafani, and Prizzi.

\section{Materials and Methods}

19 centenarians (10 females and 9 males) living at home in the five municipalities of Bisacquino, Castronovo, Chiusa Scalafani, Giuliana and Prizzi in the Western part of Sicily, Italy, were identified for the present study. These villages are located above sea-level, on the SouthWestern edge of the Sicani Mountains. Subjects were individuated by general practitioners and their age checked in the birth registries. As a further control, in the interview, particular attention was paid to the concordance between reported age and personal chronologies (age of marriage and of military service for men, age of first and last pregnancy for women, age of children, among others). The subjects underwent a physical examination and a morning fasting blood venous sample was obtained for studying blood chemistry parameters. Anthropometric measures included height, weight, and the body mass index (BMI) [weight (kg)/height (m2)]. Furthermore, the Mini Nutritional Assessment (MNA), Basic Activities of Daily Living (ADL) and the Instrumental Activities of Daily Living (IADL) were administrated. ADL and IADL were assessed by interviewing participants and their caregivers [13,14]. Physical items (meal taking, bowel and bladder continence, standing ability, extent of general activities, bathing and dressing abilities), sensory items (auditory acuity and eyesight) and cognitive abilities (comprehension and self-expression) were included in the ADL. Each item was classified into five categories of self-sufficiency: completely independent, independent but slow, independent with difficulty, partially dependent and completely dependent, using a point score from 12 to 1 , respectively.

The study was approved by local University Hospital Ethics Committee; the purpose and procedures of the study were explained to the subjects, and informed and written consent was obtained from the participants or caregivers.

\section{Results}

Table 1 depicts the prevalence of centenarians in Italy and in the study area; we have identified 19 centenarian,
10 female and 9 males among a population of 18,327 inhabitants. In this area the centenarian number was 4.32-fold higher than the national average (10.37 vs. 2.4 / $10,000)$. It is noteworthy that the male centenarian number was 11.51-fold higher than the national average (10.24 vs. $0.89 / 10,000)$. Female/male ratio was $1.1: 1$ in the study area, while the national ratio was 4.54:1.

All the centenarians live in a family home, mostly with their relatives. Individual ADL and IADL scores were in the category of moderately independent for both genders. A good anamnesis on a single individual reported a poor auditory acuity and poor eyesight, while they were free from cardiac heart disease, severe cognitive impairment, severe physical impairment, clinically evident cancer or renal insufficiency.

In Figure 1, MNA example administrated to healthy centenarian is shown [13], whereas Figure 2 reports a typical daily diet. Centenarians recruited in these area tended to be physically active, non-obese, small in stature, with a regular BMI $(23.6 \pm 3.1)$, suggestive of some degree of calorie restriction with high intake of seasonal plant food and low meat intake. Their diet shows a low glycemic index because low of refined carbohydrate (no white bread, low amount of pasta, no sweeteners, sweet beverages, can food, frozen already prepared vegetables or dishes, cookies cakes or snacks). Furthermore, they have a good intake of olive and virgin olive oil from different cultivar namely: Nocellara of Belice, Biancolilla, Giarraffa and Ogliarola that seems to have important anti-oxidant properties (unpublished data). In Figure 3, BMI and MNA are plotted together showing a perfect accordance between nutrition and body mass index.

\section{Discussion}

In Italy in 2010 the population aged one hundred years and over has 14 thousand units, hence the centenarian prevalence is $2.4 / 10.000$. Currently there are almost five centenarian women for one man. However, in Italy there is a North to South gradient in the female/male ratio in centenarians [15]. To gain insight into the role of gender and environment, we have started a demographic study in Sicily showing that in mountain zones of Sicily there is a zone of male longevity with similar features to those found in Sardinia, in the so-called Blue Zone $[11,12,16]$. In both cases the municipalities concerned do not

Table 1 Distribution of Centenarian population in five villages of Sicani Mountains and in Italy

\begin{tabular}{|c|c|c|c|c|c|c|}
\hline & Total Population & Males & Females & Total Centenarians & Male Centenarians & Female Centenarians \\
\hline \multirow[t]{2}{*}{ Sicani Mountains } & 18,328 & 8,793 & 9,535 & 19 & 9 & 10 \\
\hline & $(10.37)$ & $(10.24)$ & $(10.48)$ & & & \\
\hline \multirow[t]{2}{*}{ Italy } & $60,626,442$ & $29,413,274$ & $31,213,168$ & 14,473 & 2,612 & 11,861 \\
\hline & $(2.39)$ & $(0.89)$ & (3.80) & & & \\
\hline
\end{tabular}




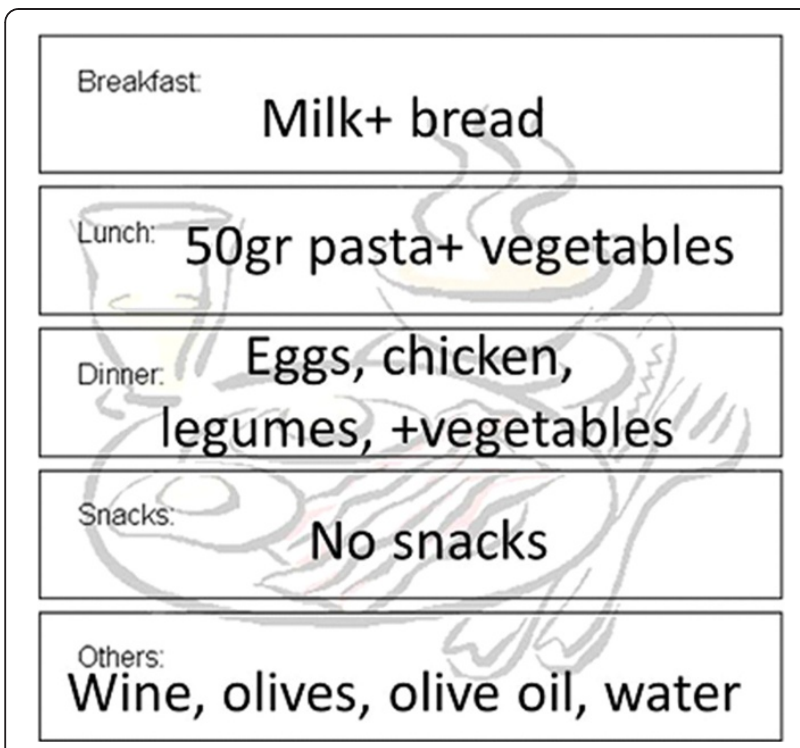

Figure 2 Example of daily menu.

include polluted areas and are small, with the lowest number of inhabitants. Therefore, longevity is more prevalent in men living in a small town, without pollution, likely because of different working conditions, different life style i.e. reduced smoking and alcohol abuse and Mediterranean diet. Accordingly, both these areas in Sicily and in Sardinia also share low mortality from cancers and cardiovascular diseases [11,16-18].
One of the places in the Western part of Sicily, characterized by a high presence of oldest old people, is the area of "Monti Sicani", between the provinces of Agrigento and Palermo [11,12]. "Monti Sicani" encompasses the area between the cities of Palermo and Agrigento from North to South and between the city of Caltanissetta and Trapani from West to East. The territory is characterized by a hilly area of clayey sandstone or pasture and a mountain area above $900 \mathrm{~m}$, consists of pelagic limestone rocks of the Mesozoic. This area is characterized by olive tree agriculture, which tolerates a large range of soil conditions, preferring a neutral to alkaline soil type.

Looking at the national ratio of centenarian per inhabitants in these area we have found more than a fourfold increase in centenarian, and regarding male female ratio of 1.1:1 times. Since Sicilian population genetics structure is very homogeneous and in Hardy-Weinberg equilibrium [19], the explanation for these data probably resides in the environmental characteristics of the study sample.

In this area, we have found a high number of centenarians in good health, with a notable increase of male centenarians. Unequivocally, their nutritional assessment showed a high adherence to the Mediterranean nutritional profile with low glycemic index food consumed. According to the scores of ADL and IADL, centenarians of both gender demonstrated a good level of independency. They did not have any cardiac risk factors or major age related diseases (e.g. cardiac heart disease, severe cognitive impairment, severe physical impairment,

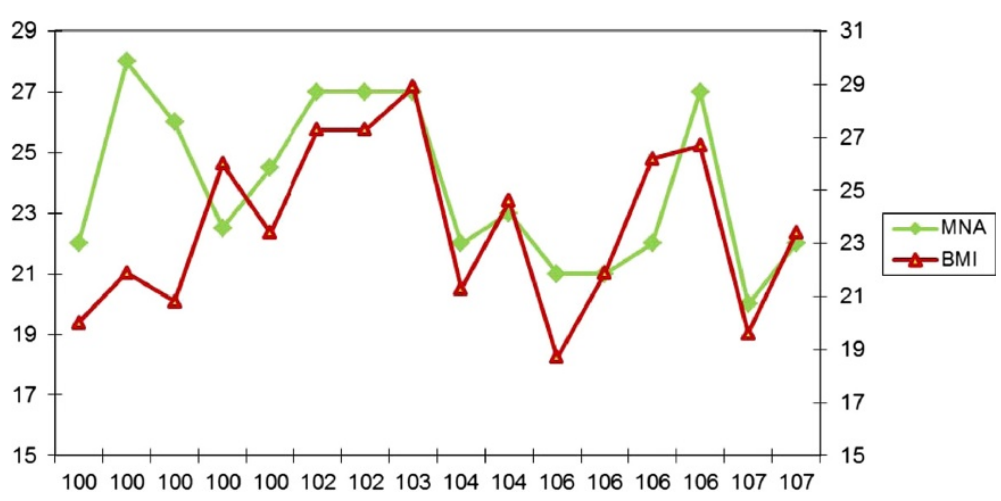

Legend:

MNA=mini nutritional assessment (17-24)

BMI= Body mass index (18-24)

On $\mathrm{x}$ axis, centenarian age

On y axis: MNA and BMI

Figure 3 Mini nutritional assessment and Body mass index in healthy centenarian population. 
clinically evident cancer or renal insufficiency), although some had decreased auditory and visual acuity. Their life is characterized by social networking, acceptable physical activity and small amount of food divided among three meals, which contain a little amount of carbohydrate and meat and a lot of seasonal fruit and vegetables. In relation to biochemical parameters in centenarians, most biochemical parameters including cholesterol and triglycerides were within normal limits (data not shown) and better than those previously reported in a study of Sicilian elderly [20]. Furthermore, this reported modified Mediterraneanstyle show a low glycemic load.

The Glycemic index (GI) is defined as a kinetic parameter that reflects the potency of food to raise blood glucose level and glucose clearance. The GI of a specific diet is calculated by averaging the GI values of the food items, statistically weighted by the carbohydrate contribution. Diets based on refined carbohydrate foods that are quickly digested, absorbed, and metabolized (i.e., high glycemic index diets) have been associated with increased risk of lifestyle diseases in particular with an increased risk of type 2 diabetes, because of postprandial hyperglycemia and hyperinsulinemia related to eating high-GI carbohydrates. Low GI is known to protect against heart disease in women, and cross-sectional studies indicate low GI may reduce high-density-lipoprotein cholesterol and triacylglycerol levels in both sexes. More interesting, new observational studies have reported increased risks of coronary heart disease associated with higher intakes of carbohydrates from high glycemic index foods. Epidemiological evidence has emerged linking dietary glycemic index to visceral fat and inflammatory disease mortality [21-23]. Therefore, the Mediterranean diet is an anti-inflammatory diet [24]: it is puzzling that Italian centenarians are remarkably enriched in "good" genotypes involved in control of inflammation, confirming that a good control of inflammatory responses (genetic and/or environmental) is advantageous for longevity $[25,26]$.

Overall, our data confirm our previous suggestion that longevity concerns subjects, living in small town, without pollution, with different working conditions, lifestyles and close adherence to a Mediterranean diet. The reason why longevity has been observed particularly in small municipalities is not surprising. It is a well established, in fact, that individuals with greater access to social support and family network have better health and lower levels of mortality, particularly when adult daughters are present. Nevertheless, our data are collected in a relative small sample of subjects; accordingly, our data needed to be confirmed by larger population-based studies.

To conclude, our work show a segment of our population that is growing faster and represent a typical example of successful ageing. Genetic and environment play a major role in healthy ageing and nutrition has a significant influence. It has been estimated that the number of centenarians will approach 3.2 million worldwide by 2050 and that means an 18-fold increase with respect to the last century [27]. Consequently, understanding the influence of dietary life-style in the process of healthy ageing is of paramount importance to development new strategies leading to healthy life extension. Finally, our results are consistent with data described in Dan Buettner's book on the importance of the diets in 5 populations with high longevity [28]. To reach successful ageing it is advisable to follow a diet with low quantity of saturated fat and high amount of fruits and vegetable, rich in phytochemicals.

\section{Competing interests}

The authors declare that they have no competing interests.

\section{Acknowledgements}

C.R. is a PhD student of PhD course in Molecular Medicine directed by C.C. and this paper is submitted in partial fulfillment of requirement for herr $\mathrm{PhD}$ degree. This work was supported by grants from the Ministry of Education, University and Research ex60\% to C.C.- The Authors are deeply indebted with Dr. Marchese for the access to centenarians living in the villages of Bisacquino, Chiusa Sclafani and Giuliana and Dr. Pizzolanti for the information on the centenarians living in Castronovo and Prizzi.

\section{Author details}

${ }^{1}$ Department of Molecular and Biomolecular Sciences (STEMBIO), University of Palermo, Via Archifari 32, 90213, Palermo, Italy. ${ }^{2}$ Department of Pathobiology and Medical and Forensic Biotechnologies (DIBIMEF), University of Palermo, Corso Tukory, 211, 90138, Palermo, Italy. ${ }^{3}$ Immunohaemathology Unit, University Hospital, University of Palermo, Via del Vespro, 127, 90137, Palermo, Italy.

\section{Authors' contributions}

SV wrote the paper. All authors edited the paper and approved its final version.

Received: 13 April 2012 Accepted: 23 April 2012

Published: 23 April 2012

\section{References}

1. Keys A, Menotti A, Karvonen MJ, Aravanis C, Blackburn H, Buzina R, Djordjevic BS, Dontas AS, Fidanza F, Keys MH, et al: The diet and 15-year death rate in the seven countries study. Am J Epidemiol 1986, 124:903-915.

2. Fidanza F, Alberti A, Lanti M, Menotti A: Mediterranean diet score: correlation with 25-year mortality from coronary heart disease in the Seven Countries Study. Nutr Metab Cardiovasc Dis 2004, 14:254-258.

3. Sacks FM, Obarzanek E, Windhauser MM, Svetkey LP, Vollmer WM, McCullough M, Karanja N, Lin PH, Steele P, Proschan MA, et al: Rationale and design of the Dietary Approaches to Stop Hypertension trial (DASH). A multicenter controlled-feeding study of dietary patterns to lower blood pressure. Ann Epidemiol 1995, 5:108-118.

4. Berry EM, Arnoni Y, Aviram M: The Middle Eastern and biblical origins of the Mediterranean diet. Public Health Nutr 2011, 14:2288-2295.

5. Tyrovolas S, Panagiotakos DB: The role of Mediterranean type of diet on the development of cancer and cardiovascular disease, in the elderly: a systematic review. Maturitas 2010, 65:122-130.

6. Sofi F, Cesari F, Abbate R, Gensini GF, Casini A: Adherence to Mediterranean diet and health status: meta-analysis. BMJ 2008, 337:a1344.

7. Fung TT, Hu FB, Wu K, Chiuve SE, Fuchs CS, Giovannucci E: The Mediterranean and Dietary Approaches to Stop Hypertension (DASH) diets and colorectal cancer. Am J Clin Nutr 2010, 92:1429-1435.

8. Bulló M, Lamuela-Raventós R, Salas-Salvadó J: Mediterranean diet and oxidation: nuts and olive oil as important sources of fat and antioxidants. Curr Top Med Chem 2011, 11:1797-1810. 
9. Aguilera CM, Mesa MD, Ramirez-Tortosa MC, Nestares MT, Ros E, Gil A: Sunflower oil does not protect against LDL oxidation as virgin olive oil does in patients with peripheral vascular disease. Clinical Nutrition 2010, 23:673-681.

10. Cicerale S, Conlan XA, Sinclair AJ, Keast RS: Chemistry and health of olive oil phenolics. Crit Rev Food Sci Nutr 2009, 49:218-236.

11. Bürkle A, Caselli G, Franceschi C, Mariani E, Sansoni P, Santoni A, Vecchio G, Witkowski JM, Caruso C: Pathophysiology of ageing, longevity and age related diseases. Immun Ageing 2007, 4:4.

12. Vasto S, Scapagnini G, Rizzo C, Monastero R, Marchese A, Caruso C: Mediterranean diet and longevity: a survey in Sicani mountains population. Rejuvenation research. 2012, 15:184-188.

13. Sancarlo D, D'Onofrio G, Franceschi M, Scarcelli C, Niro V, Addante F, Copetti M, Ferrucci L, Fontana L, Pilotto A: Prognostic Index (m-MPI) including the Mini Nutritional Assessment Short-Form (MNA-SF) for the prediction of one-year mortality in hospitalized elderly patients. I Nutr Health Aging 2011, 15:169-173.

14. Lawton MP, Brody EM: Assessment of older people: self-maintaining and instrumental activities of daily living. Gerontologist 1969, 9:179-186.

15. www.stat.unipd.it/ricerca/fulltext?wp $=388$ (in Italian)

16. Poulain M, Pes GM, Grasland C, Carru C, Ferrucci L, Baggio G, Franceschi C, Deiana $\mathrm{L}$ : Identification of a geographic area characterized by extreme longevity in the Sardinia island: the AKEA study. Exp Gerontol 2004, 39:1423-1429.

17. Caselli G, Lipsi RM: Survival differences among the oldest old in Sardinia: who, what, where, and why? DEMOGRAPHIC RESEARCH 2006, 14:267-294.

18. Marchese AG: La quarta età tra umanesimo letterario e Biomedicina. Palma Editrice, Palermo: Indagine sulla longevità dei Monti Sicani; 2011 (in Italian).

19. Piazza A, Olivetti E, Griffo RM, Rendine S, Amoroso A, Barbanti M, Caruso C, Conighi C, Conte R, Favoino B, et al: The distribution of HLA antigens in Italy. Gene Geogr 1989, 3:141-164.

20. Lio D, Malaguarnera M, Maugeri D, Ferlito L, Bennati E, Scola L, Motta M, Caruso C: Laboratory parameters in centenarians of Italian ancestry. Exp Gerontol 2008, 43:119-122.

21. McGeoch SC, Holtrop G, Fyfe C, Lobley GE, Pearson DW, Abraham P, Megson IL, Macrury SM, Johnstone AM: Food intake and dietary glycaemic index in free-living adults with and without type 2 diabetes mellitus. Nutrients 2011, 3:683-693.

22. Brand-Miller J, Buyken AE: The glycemic index issue. Curr Opin Lipidol 2012, 23:62-67.

23. Hare-Bruun H, Nielsen BM, Grau K, Oxlund AL, Heitmann BL: Should glycemic index and glycemic load be considered in dietary recommendations? Nutr Rev 2008, 66:569-590.

24. Lucas $L$, Russell A, Keast R: Molecular mechanisms of inflammation. Antiinflammatory benefits of virgin olive oil and the phenolic compound oleocanthal. Curr Pharm Des 2011, 17:754-768.

25. Candore G, Caruso C, Colonna-Romano G: Inflammation, genetic background and longevity. Biogerontology 2010, 11:565-573.

26. Vasto S, Candore G, Balistreri CR, Caruso M, Colonna-Romano G, Grimaldi MP, Listi F, Nuzzo D, Lio D, Caruso C: Inflammatory networks in ageing, age-related diseases and longevity. Mech Ageing Dev 2007, 128:83-91.

27. www.un.org/spanish/esa/population/wpp2000h.pdf

28. Buettner D: The Blue Zone: Lessons for living longer from the people who've lived the longest. Washington, DC: National Geographic Society; 2008.

\section{Submit your next manuscript to BioMed Central and take full advantage of:}

- Convenient online submission

- Thorough peer review

- No space constraints or color figure charges

- Immediate publication on acceptance

- Inclusion in PubMed, CAS, Scopus and Google Scholar

- Research which is freely available for redistribution

Submit your manuscript at www.biomedcentral.com/submit 